Original Research Paper

\title{
Antimicrobial Resistance Pattern and Characteristics of Integrons in Escherichia Coli Strains Isolated from Aquatic Retail Products in Zhejiang Province, China
}

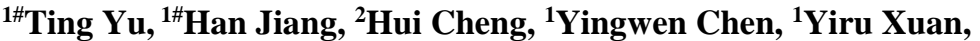 \\ ${ }^{1}$ Xiang Lv, ${ }^{1}$ Yihao Chen, ${ }^{1}$ Jingyi Gu, ${ }^{1}$ Jiehong Fang and ${ }^{1}$ Cheng Zhu \\ ${ }^{1}$ Key Laboratory of Marine Food Quality and Hazard Controlling Technology of Zhejiang Province, \\ College of Life Sciences, China Jiliang University, Hangzhou, Zhejiang 310018, People's Republic of China \\ ${ }^{2}$ Department of Research and Develop, Hangzhou Wahaha Group Co. Ltd. \\ Hangzhou, Zhejiang 310018, People's Republic of China
}

\begin{abstract}
Article history
Received: $12-10-2020$

Revised: 14-12-2020

Accepted: 15-12-2020

Corresponding Author:

Jiehong Fang

Key Laboratory of Marine Food Quality and Hazard Controlling Technology of Zhejiang Province, College of Life Sciences, China Jiliang University, Hangzhou, Zhejiang 310018, People's Republic of China

Email: fangjh@cjlu.edu.cn
\end{abstract}

\section{Cheng Zhu}

Key Laboratory of Marine Food Quality and Hazard Controlling Technology of Zhejiang Province, College of Life Sciences, China Jiliang University, Hangzhou, Zhejiang 310018, People's Republic of China

Email:pzhch@cjlu.edu.cn

\#These authors contributed equally to this work.

\begin{abstract}
The aquatic retail products are among the potential reservoirs of antimicrobial resistant microorganisms. The main objective of this study was to analyze the antimicrobial susceptibility patterns and integrons and their associated Gene Cassettes (GCs) of Escherichia coli isolates from aquatic retail products. E. coli isolates were obtained from 450 aquatic retail products samples at different markets in Zhejiang Province, China. Antimicrobial resistance among the selected isolates was studied against 19 different antibiotics by disk diffusion method and all isolates were detected for the presence of integrase genes and Gene Cassettes (GCs) using PCR assays. The results showed that a total of 181 (40.22\%) E. coli were obtained and the resistance pattern in the isolates was highly variable and significant differences were observed between seven antibiotics $(\mathrm{p}<0.05)$. Furthermore, 65.19\% (118/181) of the isolates exhibited Multi-Drug Resistance (MDR) and the multiple resistance patterns were highly diverse with 77 different ones. Additionally, multiple-antibiotic resistance index values of more than 0.2 were determined in $62.43 \%$ of the isolates, which were diversely distributed in the three aquatic products. Of the $181 \mathrm{E}$. coli isolates obtained, 56 (30.94\%) were positive for class 1 integrons and five $(2.76 \%)$ were positive for class 2 integrons. Among these, $31 \mathrm{GCs}$ with nine different arrays were detected in class 1 integrons and five GCs with two different arrays were detected in class 2 integrons. This study suggests that aquatic products may act as a reservoir and facilitate the dissemination of MDR.
\end{abstract}

Keywords: Antimicrobial Resistance Patterns, Multi-Drug Resistance, Multiple-Antibiotic Resistance Index Values, Gene Cassette Arrays

\section{Introduction}

Antibiotics have been used routinely for the prophylaxis and therapy of bacterial infection as well as growth promotion in animals for several decades (Fang et al., 2019). However, with the large-scale and intensive development of the farming industry, animal diseases have increased and the increasing and inappropriate use of antibiotics has led to the emergence and spread of Antimicrobial-Resistant (AMR) bacteria (He et al., 2016; Kang et al., 2018). In particular, the overuse and misuse of antibiotics have accelerated the occurrence of Multi-Drug Resistant (MDR) bacteria and even "super bacteria," which are emerging to harm the environment and endanger public and animal health (Park et al., 2018; Li et al., 2020).

MDR is mainly due to the Horizontal Gene Transfer (HGT) of Antimicrobial Resistance Genes (ARGs) by Mobile Genetic E (MGEs) (Top and Springaely, 2003; Baharoglu et al., 2010). The HGT of bacteria through MGEs can confer the adaptive evolution of bacteria in a changing environment and promote the rapid proliferation of ARGs between different bacterial species, even in human pathogens (Martínez, 2008; Zhu et al., 2017; Beridze et al., 2020). 
Integrons are one of bacterial MGEs that play an important role in the acquisition, expression, dissemination and distribution of ARGs between strains (Stalder et al., 2012; Fang et al., 2019; Trang et al., 2020). Integrons are composed of three elements: (a) The integrase gene (intI), which encodes an integrase protein IntI and mediates the integration and excision of the Gene Cassettes (GCs) through site-specific RecAindependent recombination; (b) a specific recombination site attI; and (c) a Pc promoter (Barraud and Ploy, 2015; Li et al., 2018; Dokić et al., 2020). Relative to the amino acid sequence of the IntI integrase protein, five general classes of integrons have been identified and distinguished (Theingi et al., 2019), Classes 1, 2 and 3 are detected in descending order and Classes 4 and 5 are rarely detected (Hochhut et al., 2001; Stalder et al., 2012; Lae et al., 2019).

Escherichia coli are ubiquitous commensal bacteria, some strains can be pathogenic to humans (Rehman et al., 2017; Ebrahimipour et al., 2020). Studies have found that AMR in the Enterobacteriaceae family has increased significantly in the past few years due to the abuse of antibiotics (Shaikh et al., 2015; Liu et al., 2017; Manikandan et al., 2020). Additionally, E. coli has a wide range of hosts and resistance genes can be easily obtained through HGT. Thus, E. coli is often used to monitor the occurrence of AMR (Huddleston, 2014; Paraoan et al., 2017).

Since 2002, China has become the world's largest producer and consumer of aquatic products (FAO, 2002). However, in China, a high occurrence of AM R bacteria has already been detected in aquatic products and their related environments especially in coastal regions of southeastern China (Shao et al., 2018; Jiang et al., 2019). To our knowledge, little comprehensive research has been conducted on antibiotic resistance in $E$. coli isolates from both crustaceans, fish and shellfish in coastal region of southeastern China.

Thus, in this study, we selected three popular and important aquatic products in China: Pacific whiteleg shrimps ( $P$. vannamei), Pacific mackerels (Pneumatophorus japonicus) and Pacific oysters (Crassostrea gigas) to represent crustaceans, fish and shellfish, respectively. The samples were obtained from different markets in Zhejiang Province, a representative coastal region in southeastern China with high production and consumption of important aquatic products. The aim was to analyze the antimicrobial susceptibility profiles and integrons and the associated GCs of $E$. coli isolates. This information will help monitor the changes in AMR of E. coli isolated from aquatic products in China and will provide insight into the appropriate use of antibiotics and the safe consumption of aquatic products. The remainder of present paper is organized as follows. Section 2 briefly describes the method of sample collection, isolation of $E$. coli isolates, antimicrobial susceptibility testing of the isolates, the detection of integrons and statistical analysis of drug resistance in the $E$. coli isolates from different samples. The isolation rates of $E$. coli from aquatic product samples, the antibiotic resistance profiles of $E$. coli isolates for 19 antibiotics from nine classes and the prevalence of integrons in $E$. coli isolates will be presented in section 3. Section 4 provides the conclusion and prospect of this paper.

\section{Materials}

\section{Sample Collection}

A total of 450 samples from Pacific whiteleg shrimps (P. vannamei; $n=150$ ), Pacific mackerels ( $P$. japonicus; $n$ $=150)$ and Pacific oysters $(C$. gigas; $n=150)$ were collected evenly from five different retail markets in Zhejiang Province, China between July and August 2019. Each sample was dispensed into a sterile sealed sampling bag and shipped back to the laboratory in an icebox within $2 \mathrm{~h}$ for bacterial isolation in a sterile environment.

\section{Isolation and Identification of E. coli Strains}

Meat (10 g) from each Pacific whiteleg shrimp, Pacific mackerel and Pacific oyster was used for E. coli isolation. Each sample was mixed with sterile LuriaBertani (LB) broth (Hope Bio-Technology Co., Qingdao, China) $(1: 1, \mathrm{w} / \mathrm{v})$ and homogenized for $2 \mathrm{~min}$ in a homogenizer (Scieatz, Ningbo, China). Homogenates were incubated overnight (about 16-18 h) in a shaker at $37^{\circ} \mathrm{C}, 200 \mathrm{rpm}$ for pre-enrichment. A $50 \mu \mathrm{L}$ aliquot of the overnight cultivated broth used in primary isolation was transferred to Eosin Methylene Blue (EMB) agar plates (Hope Bio-Technology Co.) and incubated at $37^{\circ} \mathrm{C}$ for $24 \mathrm{~h}$. Thereafter, colonies with a green metallic sheen on EMB plates were presumed to be $E$. coli and inoculated into $\mathrm{LB}$ broth at $37^{\circ} \mathrm{C}$ for $16-18 \mathrm{~h}$ and then kept at $-20^{\circ} \mathrm{C}$. Because the microbial cells from the top of the homogenates mentioned above were enriched with many of the same colonies, one E. coli isolate per sample was selected for further analysis, as done in previous studies (Cheng et al., 2019; Fang et al., 2019).

Polymerase Chain Reaction (PCR) was used to detect the uidA gene (Cheng et al., 2019). Genomic DNA templates of putative $E$. coli strains were isolated using a Bacteria Genomic DNA Kit (Kangwei Century Biotechnology Co. Ltd., Beijing, China). E. coli ATCC 25922 was used as a positive control. The design of primers was based on the uidA gene (Table 1) (Fang et al., 2019). Each PCR reaction mixture consisted 5 U of ExTaq DNA polymerase (Takara-Bio, Dalian, China), 200 $\mathrm{mM}$ of each deoxynucleotide triphosphate, 10× PCR buffer, $400 \mathrm{nM}$ of each primer, $250 \mathrm{ng}$ of DNA template 
and double-distilled water $\left(\mathrm{ddH}_{2} \mathrm{O}\right)$ to a total volume of $25 \mu \mathrm{L}$. PCR amplification included pre-denaturation at $98^{\circ} \mathrm{C}$ for $1 \mathrm{~min}$, followed by 35 cycles of denaturation at $98^{\circ} \mathrm{C}$ for $30 \mathrm{~s}$, annealing at $56^{\circ} \mathrm{C}$ for $30 \mathrm{~s}$ and polymerization at $72^{\circ} \mathrm{C}$ for $30 \mathrm{~s}$ and a final extension at $72^{\circ} \mathrm{C}$ for $10 \mathrm{~min}$. The PCR products were electrophoresed on a $1.2 \%$ agarose gel stained with GoldView II (Gentihold, Beijing, China) (Fig. 1).

\section{Antimicrobial Susceptibility Testing}

E. coli isolates $(n=181)$ were tested for antimicrobial susceptibility according to the Kirby-Bauer disk diffusion method recommended by the Clinical and Laboratory Standards Institute (CLSI, 2019). Nineteen antimicrobial agents of nine different classes: $\beta$-lactam (ampicillin, $10 \mu \mathrm{g}$; cefazolin, $30 \mu \mathrm{g}$; cefamandole, $30 \mu \mathrm{g}$; ceftizoxime, $30 \mu \mathrm{g}$; cefepime, $30 \mu \mathrm{g}$; meropenem, 10 $\mu \mathrm{g}$ ), polypeptide (polymyxin B, $300 \mathrm{IU}$ ), furan (furazolidone, $100 \mu \mathrm{g}$ ), tetracycline (tetracycline, $30 \mu \mathrm{g}$; doxycycline, $30 \mu \mathrm{g}$ ), sulfonamides (trimethoprimsulfamethoxazole, $1.25 / 23.75 \mu \mathrm{g}$; sulfadiazine, $300 \mu \mathrm{g}$ ), macrolide (erythromycin, $15 \mu \mathrm{g}$ ), quinolone (enrofloxacin, $10 \mu \mathrm{g}$; lomefloxacin, $10 \mu \mathrm{g}$ ), chloramphenicol (florfenicol, $30 \mu \mathrm{g}$; chloramphenicol, $30 \mu \mathrm{g}$ ), aminoglycoside (spectinomycin, $100 \mu \mathrm{g}$; neomycin, $30 \mu \mathrm{g}$ ), were obtained from Hangzhou Microbiology Co. Ltd. (Hangzhou, China). All confirmed E. coli isolates were incubated at $37^{\circ} \mathrm{C}$ overnight and diluted to a $0.5 \mathrm{McFarl}$ and standard with $0.9 \%(w / v) ~ N a C l$ then transferred to Mueller-Hinton agar (Hope Bio-Technology Co.) plates with a sterile cotton swab and incubated at $37^{\circ} \mathrm{C}$ for $16-18 \mathrm{~h}$. Interpretation of inhibition zones was performed according to the CLSI guidelines and classified as Resistant (R), Intermediate (I), or Susceptible (S). E. coli ATCC 25922 was used as a quality control strain. MDR was defined as $E$. coli strains exhibiting resistance to three or more classes of antimicrobials (Schwarz et al., 2010). MultipleAntibiotic Resistance (MAR) index was calculated (MAR index $=a / b$, where $a$ is the number of antibiotics with which the isolate was resistant and b is the total number of antibiotics tested) (Krumperman, 1983).

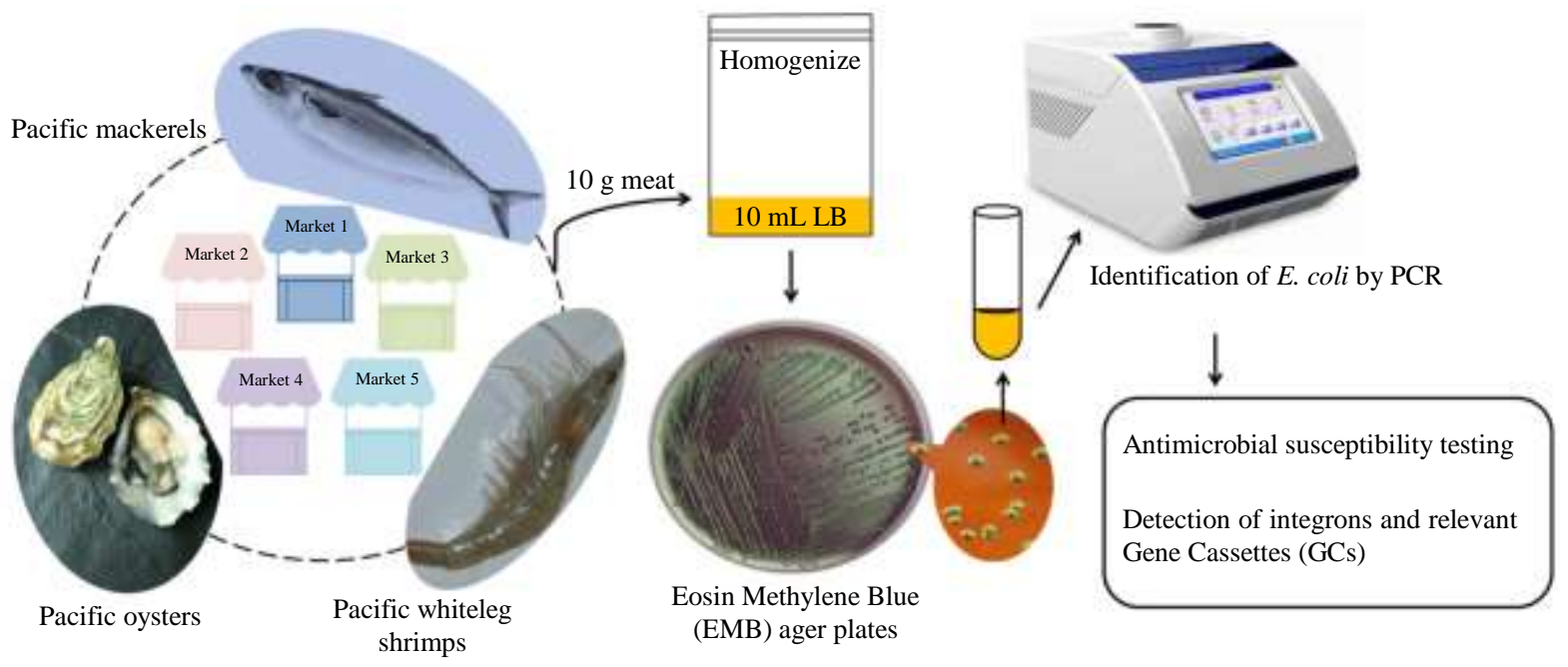

Fig. 1: Research methods in this study

Table 1: Primers used in this study

\begin{tabular}{|c|c|c|c|c|}
\hline Target & Primer & Sequence $\left(5^{\prime}-3{ }^{\prime}\right)$ & Amplicon size (bp) & Reference \\
\hline \multirow[t]{2}{*}{ uidA } & uidA-F & GTCCTGTAGAAACCCCAACCCGTGAA & & \\
\hline & uidA-R & GGGATAGTCTGCCAGTTCAGTTCGT & 424 & Fang et al. (2019) \\
\hline \multirow[t]{2}{*}{ intII } & intI1-F & GGCTTCGTGATGCCTGCTT & & \\
\hline & intI1-R & CATTCCTGGCCGTGGTTCT & 146 & Luo et al. (2010) \\
\hline \multirow[t]{2}{*}{ int 12} & intI2-F & CACGGATATGCGACAAAAAGGT & & \\
\hline & intI2-R & GTAGCAAACGAGTGACGAAATG & 789 & Odumosu et al. (2013) \\
\hline \multirow[t]{2}{*}{ intI3 } & intI3-F & GCCTCCGGCAGCGACTTTCAG & & \\
\hline & intI3-R & ACGGATCTGCCAAACCTGACT & 980 & White et al. (2001) \\
\hline Class 1 integron & hep58 & TCATGGCTTGTTATGACTGT & Class 1 integron & Odumosu et al. (2013) \\
\hline variable region & hep59 & GTAGGGCTTATTATGCACGC & variable region & \\
\hline Class 2 integron & hep51 & GATGCCATCGCAAGTACGAG & Class 2 integron & White et al. (2001) \\
\hline variable region & hep74 & CGGGATCCCGGACGGCATGCACGATTTGTA & variable region & \\
\hline
\end{tabular}


Detection of Integrons and Relevant Gene Cassettes (GCs)

All isolates were detected for the presence of integrase genes (intII, int/2 and intI3) and GCs using PCR assays. The primers used for these genes are listed in Table 1 (Luo et al., 2010; Odumosu et al., 2013). The genomic DNA extraction and PCR reaction mixture are as described previously (section 2.2). Amplification was initiated by incubating the reaction mixture at $94^{\circ} \mathrm{C}$ for 1 min followed by 35 cycles of $30 \mathrm{~s}$ at $98^{\circ} \mathrm{C}$, annealing at $55^{\circ} \mathrm{C}$ (intIl and intI2) or $60^{\circ} \mathrm{C}$ (intI3) for $30 \mathrm{~s}$, an extension for 30s (intII) or $1 \mathrm{~min}$ (intI2 and intI3) at $72^{\circ} \mathrm{C}$ and a final extension at $72^{\circ} \mathrm{C}$ for $10 \mathrm{~min}$.

Although the int 13 gene was not detected in any identified E. coli strains, the Variable Regions (VRs) of strains that were positive for the intI 1 and/or int $I 2$ genes were further analyzed by PCR. For intI1-positive E. coli isolates, PCR amplification annealed at $55^{\circ} \mathrm{C}$ for $30 \mathrm{~s}$ and extended at $72^{\circ} \mathrm{C}$ for $4 \mathrm{~min}$ with primers hep58hep59 (Odumosu et al., 2013). For intI2-positive E. coli isolates, the procedure was as follows: Pre-denaturation $\left(98^{\circ} \mathrm{C}, 1 \mathrm{~min}\right)$, followed by 12 cycles of denaturation $\left(98^{\circ} \mathrm{C}, 30 \mathrm{~s}\right)$, annealing $\left(68^{\circ} \mathrm{C}, 30 \mathrm{~s}\right.$; an initial temperature of $68^{\circ} \mathrm{C}$ decreasing by $1^{\circ} \mathrm{C}$ each cycle), extension $\left(72^{\circ} \mathrm{C}, 1 \mathrm{~min}\right)$ and followed by 30 cycles of denaturation $\left(98^{\circ} \mathrm{C}, 30 \mathrm{~s}\right)$, annealing $\left(56^{\circ} \mathrm{C}, 30 \mathrm{~s}\right)$, extension $\left(72^{\circ} \mathrm{C}, 4 \mathrm{~min}\right)$ and a final extension $\left(72^{\circ} \mathrm{C}, 10\right.$ min) with primer pairs hep51-hep74 (White et al., 2001). The products were subsequently sequenced by Shanghai Sangon (Shanghai, China) and sequences were compared with the GenBank reference sequences using NCBI BLAST (www.ncbi.nlm.nih.gov/blast/).

\section{Statistical Analysis}

All experiments were performed in triplicate. Data analysis was performed by SPSS (version 20.0). Independent sample t-tests were used for the analysis of drug resistance in the E. coli isolates from different samples against different antibiotics and significant differences were assigned when $p<0.05$.

\section{Results}

\section{E. coli Isolates}

A total of $181(40.22 \%)$ E. coli isolates were obtained from 450 aquatic product samples. Of these, $51.33 \%$ (77/150) were from Pacific whiteleg shrimps, $40.00 \%$ (60/150) were from Pacific mackerels and $29.33 \%$ (44/150) were from Pacific oysters.

\section{Antibiotic Resistance Profiles of E. coli Isolates}

The antibiotic resistance profiles of $181 \mathrm{E}$. coli isolates for 19 antibiotics from nine classes are displayed in Table 2. Overall, E. coli strains showed relatively higher resistance to enrofloxacin $(59.12 \%, 107 / 181)$, erythromycin $(47.51 \%, 86 / 181)$ and tetracycline $(40.33 \%, 73 / 181)$. In addition, these isolates exhibited moderate resistance rates for ampicillin $(37.02 \%$, 67/181), cefazolin $(32.60 \%$, 59/181), doxycycline $(32.04 \%, 58 / 181)$, furazolidone $(29.83 \%, 54 / 181)$, polymyxin B $(27.62 \%, 50 / 181)$, sulfadiazine $(25.97 \%$, $47 / 181)$, florfenicol $(21.55 \%$, 39/181), trimethoprimsulfamethoxazole $(20.44 \%, 37 / 181)$, chloramphenicol $(17.68 \%, 32 / 181)$ and lomefloxacin $(10.50 \%, 19 / 181)$. Low levels of resistance were observed for spectinomycin $(4.97 \%, 9 / 181)$, cefamandole $(4.42 \%$, $8 / 181)$, cefepime $(4.42 \%, 8 / 181)$, meropenem $(3.87 \%$, $7 / 181)$, ceftizoxime $(3.31 \%, 6 / 181)$ and neomycin $(2.21 \%, 4 / 181)$. Individually, in Pacific whiteleg shrimp samples, E. coli isolates showed the highest resistance to enrofloxacin $(50.65 \%, 39 / 77)$ and no resistance to ceftizoxime, cefepime and meropenem; in Pacific mackerel samples, E. coli isolates showed the highest resistance to erythromycin $(61.67 \%, 37 / 60)$ and no resistance to neomycin; and in Pacific oyster samples, E. coli isolates showed the highest resistance to enrofloxacin $(72.73 \%, 32 / 44)$ and no resistance to cefamandole, cefepime and meropenem. Furthermore, independent sample t-tests revealed that resistant rates of strains to ampicillin, cefazolin, doxycycline, lomefloxacin, enrofloxacin, florfenicol and chloramphenicol were significantly different among the three different species $(p<0.05)$, while resistant rates to spectinomycin and neomycin were not significantly different among the three species $(p>0.05)$. It seems that $E$. coli isolates exhibited high rates of resistance to several older antibiotics, including enrofloxacin, erythromycin and tetracycline, that have commonly been used in animal husbandry in China for many years (Gong et al., 2013).

Additionally, results showed that $65.19 \%$ (118/181) of $E$. coli isolates were classified as MDR (Pacific whiteleg shrimps, 51.95\%, 40/77; Pacific mackerels, 71.67\%, 43/60; and Pacific oysters, 79.55\%, 35/44). The multiple resistance patterns were highly diverse with 77 different patterns and the most common pattern was the combination of furazolidone/erythromycin/enrofloxacin observed in three E. coli isolates: One from Pacific whiteleg shrimp samples and two from Pacific oyster samples. Furthermore, MAR index values were between 0 and 0.68 with an abundance of 92 different resistance patterns (data not shown). The MAR index values of most isolates were $0.21,0.26$ and 0.37 (each 14 isolates), but was as high as 0.68 in two isolates that were resistant to 13 antibiotics (Table 3). In aquaculture, antibiotics are used to control bacterial infections and promote growth (Tan et al., 2017). It is a common practice to add antibiotics to feed and water bodies. In addition, the 
widespread use of antibiotics in clinics, agriculture and livestock production has also promoted the spread of drug-resistant bacteria, which also explains the multiple MDR patterns found in our research (Tan et al., 2017;
Yassin et al., 2017). Although the prevalence of MDR was higher than that reported in our previous researches, it was still lower than that reported for animal husbandry in China (Cheng et al., 2019; Zhang et al., 2017).

Table 2: Antibiotic susceptibility profiles of 181 E. coli isolates

\begin{tabular}{|c|c|c|c|c|c|}
\hline \multirow[b]{2}{*}{ Antibiotics } & \multirow[b]{2}{*}{$\begin{array}{l}\text { Breakpoints } \\
\text { (CLSI, 2019) } \\
\text { R, I, S (mm) }\end{array}$} & \multicolumn{4}{|c|}{ Resistant isolates (\%) } \\
\hline & & $(n=77)$ & $\begin{array}{l}\text { Pacific mackerels } \\
(n=60)\end{array}$ & $\begin{array}{l}\text { Pacific oysters } \\
(n=44)\end{array}$ & $\begin{array}{l}\text { Total } \\
(n=181)\end{array}$ \\
\hline \multicolumn{6}{|l|}{$\beta$-Lactams } \\
\hline $\mathrm{AM}$ & $\leq 13|14-16| \geq 17$ & 20.78 & 43.33 & 56.82 & 37.02 \\
\hline $\mathrm{CZ}$ & $\leq 19|20-22| \geq 23$ & 31.17 & 50.00 & 11.36 & 32.60 \\
\hline $\mathrm{CM}$ & $\leq 14|15-17| \geq 18$ & 2.60 & 10.00 & 0.00 & 4.42 \\
\hline $\mathrm{ZOX}$ & $\leq 21|22-24| \geq 25$ & 0.00 & 6.67 & 4.55 & 3.31 \\
\hline FEP & $\leq 18|19-24| \geq 25$ & 0.00 & 13.33 & 0.00 & 4.42 \\
\hline MEM & $\leq 19|20-22| \geq 23$ & 0.00 & 11.67 & 0.00 & 3.87 \\
\hline \multicolumn{6}{|l|}{ Polymyxins } \\
\hline $\mathrm{PB}$ & $\leq 12|13-19| \geq 20$ & 20.78 & 43.33 & 18.18 & 27.62 \\
\hline \multicolumn{6}{|l|}{ Furan } \\
\hline $\mathrm{FZ}$ & $\leq 14|15-16| \geq 17$ & 23.38 & 48.33 & 15.91 & 29.83 \\
\hline \multicolumn{6}{|l|}{ Tetracyclines } \\
\hline TET & $\leq 11|12-14| \geq 15$ & 32.47 & 60.00 & 27.27 & 40.33 \\
\hline DOX & $\leq 10|11-13| \geq 14$ & 15.58 & 53.33 & 31.82 & 32.04 \\
\hline \multicolumn{6}{|l|}{ Sulfonamides } \\
\hline TMP-SMZ & $\leq 10|11-15| \geq 16$ & 11.69 & 13.33 & 45.45 & 20.44 \\
\hline SZE & $\leq 10|11-15| \geq 16$ & 18.18 & 21.67 & 45.45 & 25.97 \\
\hline \multicolumn{6}{|l|}{ Macrolides } \\
\hline ERY & $\leq 12|12-23| \geq 24$ & 38.96 & 61.67 & 43.18 & 47.51 \\
\hline \multicolumn{6}{|l|}{ Quinolones } \\
\hline LOM & $\leq 18|19-21| \geq 22$ & 9.09 & 3.33 & 22.73 & 10.50 \\
\hline ENR & $\leq 27|28-36| \geq 37$ & 50.65 & 60.00 & 72.73 & 59.12 \\
\hline \multicolumn{6}{|l|}{ Amphenicols } \\
\hline FLO & $\leq 11|12-18| \geq 19$ & 11.69 & 16.67 & 45.45 & 21.55 \\
\hline CHL & $\leq 12|13-17| \geq 18$ & 9.09 & 18.33 & 31.82 & 17.68 \\
\hline \multicolumn{6}{|c|}{ Aminoglycosides } \\
\hline SPT & $\leq 14|15-17| \geq 18$ & 3.90 & 5.00 & 6.82 & 4.97 \\
\hline NEO & $\leq 11|12-14| \geq 15$ & 2.60 & 0.00 & 4.55 & 2.21 \\
\hline MDR & & 51.95 & 71.67 & 79.55 & 65.19 \\
\hline \multicolumn{6}{|c|}{$\begin{array}{l}N=\text { Number of Investigated } E . \text { coli } \text { Isolates; R = Resistance; I = Intermediate Resistance; S = Susceptible; AM, Ampicillin; CZ, } \\
\text { Cefazolin; CM, Cefamandole; ZOX, Ceftizoxime; FEP, Cefepime; MEM, Meropenem; PB, Polymyxin B; FZ, Furazolidone; TET, } \\
\text { Tetracycline; DOX, Doxycycline; TMP-SMZ, Trimethoprim-Sulfamethoxazole; SZE, Sulfadiazine; ERY, Erythromycin; LOM, } \\
\text { Lomefloxacin; ENR, Enrofloxacin; FLO, Florfenicol; CHL, Chloramphenicol; SPT, Spectinomycin; NEO, Neomycin }\end{array}$} \\
\hline \multicolumn{6}{|c|}{ Table 3: MAR index values of E. coli isolat } \\
\hline MAR index & No. of isolates & \multicolumn{3}{|c|}{ Origin $(n)$} & \\
\hline 0 & 19 & \multicolumn{4}{|c|}{ Pacific whiteleg shrimps (15); Pacific mackerels (3); Pacific oysters (1) } \\
\hline 0.05 & 19 & \multicolumn{4}{|c|}{ Pacific whiteleg shrimps (7); Pacific mackerels (9); Pacific oysters (3) } \\
\hline 0.11 & 19 & \multicolumn{4}{|c|}{ Pacific whiteleg shrimps (6); Pacific mackerels (10); Pacific oysters (3) } \\
\hline 0.16 & 11 & \multicolumn{4}{|c|}{ Pacific whiteleg shrimps (5); Pacific mackerels (2); Pacific oysters (4) } \\
\hline 0.21 & 20 & & hiteleg shrimps (4); & c mackerels (9); & ysters (7) \\
\hline 0.26 & 20 & & hiteleg shrimps (7); & c mackerels (9); & ysters (4) \\
\hline 0.32 & 18 & & hiteleg shrimps (2); & c mackerels (13) & oysters (3) \\
\hline 0.37 & 20 & & hiteleg shrimps (4); & c mackerels (9); & ysters (7) \\
\hline 0.42 & 19 & & hiteleg shrimps (3); & c mackerels (12) & oysters (4) \\
\hline 0.47 & 7 & & hiteleg shrimps (2); & c mackerels (5) & \\
\hline 0.53 & 6 & & hiteleg shrimps (3); & c mackerels (3) & \\
\hline 0.63 & 1 & & lackerels (1) & & \\
\hline 0.68 & 2 & & lackerels (2) & & \\
\hline
\end{tabular}


Table 4: Integrons and cassette arrays identified in $181 \mathrm{E}$. coli isolates

\begin{tabular}{|c|c|c|c|c|}
\hline Gene cassette array & Source & $\begin{array}{l}\text { No. of } \\
\text { isolates }\end{array}$ & $\begin{array}{l}\text { Size } \\
\text { (bp) }\end{array}$ & Antibiotic resistance profile (n) \\
\hline \multicolumn{5}{|l|}{ Class 1 Integrons } \\
\hline \multirow[t]{3}{*}{ aadAl } & Pacific whiteleg shrimps & 3 & 750 & $\begin{array}{l}\text { AM-CZ-PB-FZ-DOX-TMP-SMZ-ERY-ENR (2); } \\
\text { CZ-PB-FZ-TET-ERY-LOM (1) }\end{array}$ \\
\hline & Pacific mackerels & 3 & & $\begin{array}{l}\text { AM-CZ-MEM-FZ-TET-DOX-SZE-ERY-LOM- } \\
\text { ENR-FLO-CHL (1); FZ-TET-ERY-ENR (2) }\end{array}$ \\
\hline & Pacific oysters & 2 & & FZ-ERY-ENR (2) \\
\hline \multirow[t]{3}{*}{ aadA2 } & Pacific whiteleg shrimps & 2 & 791 & $\begin{array}{l}\text { AM-PB-FZ-TET-ERY-LOM (1); CM-TMP-SMZ- } \\
\text { ERY-ENR (1) }\end{array}$ \\
\hline & Pacific mackerels & 3 & & $\begin{array}{l}\text { CZ-PB-FZ-TET-DOX-ERY-ENR-FLO (1); } \\
\text { PB-FZ-TET-DOX-ERY-ENR (2) }\end{array}$ \\
\hline & Pacific oysters & 2 & & $\begin{array}{l}\text { AM-CZ-PB-TMP-SMZ-SZE-ENR-FLO-NEO (1); } \\
\text { AM-TET-TMP-SMZ-SZE -ENR-FLO-CHL (1) }\end{array}$ \\
\hline \multirow[t]{2}{*}{ dfrA17-aadA5 } & Pacific whiteleg shrimps & 1 & 1391 & FZ-TET-DOX-TMP-SMZ-SZE-ENR-FLO (1) \\
\hline & Pacific mackerels & 2 & & AM-TET-DOX-SZE-ERY-ENR-FLO-CHL (2) \\
\hline \multirow[t]{2}{*}{ dfrA12-aadA2 } & Pacific whiteleg shrimps & 1 & 1704 & PB-ERY-ENR (1) \\
\hline & Pacific mackerels & 2 & & $\begin{array}{l}\text { AM-CZ-CM-PB-FZ-TET-DOX-TMP-SMZ-SZE- } \\
\text { ERY-ENR-FLO-CHL (1); MEM-PB-TET-ENR (1) }\end{array}$ \\
\hline \multirow[t]{3}{*}{ dfrAl-aadAl } & Pacific whiteleg shrimps & 1 & 1357 & AM-CM-TET-ENR (1) \\
\hline & Pacific mackerels & 1 & & TET-TMP-SMZ-SZE-ERY (1) \\
\hline & Pacific oysters & 2 & & TET-DOX-TMP-SMZ-SZE -ENR-FLO-CHL (2) \\
\hline aadB-aadA1-cmlA6 & Pacific whiteleg shrimps & 2 & 2903 & AM-CZ-SZE-CHL (2) \\
\hline $\operatorname{arr} 3-a a c\left(6^{\prime}\right)-I b$ & Pacific whiteleg shrimps & 2 & 1148 & AM-PB-TET-ERY-ENR (2) \\
\hline dfrA12-orf-aadA2 & Pacific mackerels & 1 & 1696 & $\begin{array}{l}\text { AM-CZ-CM-MEM-FZ-TET-DOX- } \\
\text { TMP-SMZ-SZE -ERY-ENR (1) }\end{array}$ \\
\hline orf & Pacific oysters & 1 & 290 & AM-DOX-ENR (1) \\
\hline \multicolumn{5}{|l|}{ Class 2 Integrons } \\
\hline \multirow[t]{3}{*}{ dfr $\mathrm{A} 1-\operatorname{sat} 2-\operatorname{aad} \mathrm{A} 1$} & Pacific whiteleg shrimps & 1 & 1938 & CZ-PB-FZ-TET-ERY-ENR-SPT (1) \\
\hline & Pacific mackerels & 2 & & $\begin{array}{l}\text { AM-TMP-SMZ-SZE -ENR-CHL (1); } \\
\text { CZ-FZ-TET-DOX-ERY-ENR (1) }\end{array}$ \\
\hline & Pacific oysters & 1 & & DOX-TMP-SMZ-SZE -ENR-FLO-CHL (1) \\
\hline dfrA1-catB2-sat2-aadA1 & Pacific whiteleg shrimps & 1 & 2697 & CZ-DOX-ERY-LOM-ENR (1) \\
\hline
\end{tabular}

AM, Ampicillin; CZ, Cefazolin; CM, Cefamandole; MEM, Meropenem; PB, Polymyxin B; FZ, Furazolidone; TET, Tetracycline; DOX, Doxycycline; TMP-SMZ, Trimethoprim-Sulfamethoxazole; SZE, Sulfadiazine; ERY, Erythromycin; LOM, Lomefloxacin; ENR, Enrofloxacin; FLO, Florfenicol; CHL, Chloramphenicol; SPT, Spectinomycin; NEO, Neomycin

\section{Prevalence of Integrons in E. coli Isolates and Associated GCs}

Of the 181 E. coli isolates identified, 56 (30.94\%) were positive for intIl and five (2.76\%) were positive for intI2. All intI2-positive strains were also carrying intII. However, no intI3-positive isolates were detected in our study. The prevalence of class 1 and class 2 integrons in $E$. coli isolates and their associated GCs (where possible) from different samples are shown in Table 4.

Of the 56 intI1-positive isolates identified, 31 (55.36\%) were positive for GCs and nine distinct types of GCs arrays were identified by VR fragment sequencing. In addition, of the 5 intI2-positive isolates, 5 $(100 \%)$ were positive for GCs and two different types of GCs arrays were identified. Third, no E. coli isolates contained both GCs of class 1 integrons and GCs of class 2 integrons. Table 4 summarizes the sizes and the antibiotic resistance profiles associated with the different GCs. In total, four streptomycin and spectinomycin resistance genes (aadB, aadA1, aadA2 and aadA5), three trimethoprim resistance genes (dfrAl, $d f r A l 2$ and dfrA17), one chloramphenicol resistance gene (cmlA6), one rifampin resistance gene (arr3), one amikacin resistance gene $\left(a a c\left(6^{\prime}\right)-I b\right)$, one streptothricin resistance gene (sat2), one amphenicol resistance gene (catB2) and one open reading frame of unknown function (orf) were detected. It was noted that all E. coli isolates carrying GCs were MDR isolates. Similar to previous studies, intIl is most present in the environment and may be related to its structure, while intI3 is rarely detected in the environment. In addition, it has been reported that $d r f A$ and $a a d A$ resistance genes are highly stable and low cost structures which are commonly found in class 1 and class 2 integrons (Paraoan et al., 2017; Dib et al., 2018).

\section{Discussion}

Many studies have reported that a large amount of antibiotics has already been discharged into aquatic 
environments (Cabello et al., 2013; Shimizu et al., 2013; Zhang et al., 2015). Under this selective pressure, the occurrence of AMR bacteria and ARGs and their transmission between the same or different bacteria in aquatic species have developed into a global concern (Shao et al., 2018). At present, a high prevalence of AMR E. coli isolates has already been detected in many aquatic products worldwide (Lin et al., 2016; Jiang et al., 2019). In our study, we characterized antimicrobial resistance profiles and integrons and their associated GCs of $E$. coli strains isolated from three species of aquatic products sold at different markets in Zhejiang Province, China.

In our findings, the strains had highly variable resistance patterns and significant differences were observed in the resistant rates of seven antibiotics, belonging to $\beta$-Lactams, tetracyclines, quinolones and amphenicols classes, between isolates from Pacific whiteleg shrimp, Pacific mackerel and Pacific oyster samples $(p<0.05)$. Resistance patterns were highly diverse as can be seen in Table 2 and only resistant rates to aminoglycosides displayed no significant difference in strains from three aquatic products $(p>0.05)$. Overall, in $E$. coli isolates the highest resistance rate was observed for enrofloxacin $(59.12 \%)$, followed by erythromycin $(47.51 \%)$, tetracycline $(40.33 \%)$ and ampicillin $(37.02 \%)$. These resistance rates were quite different when compared to other studies as ampicillin was always the highest (Lin et al., 2016; Dib et al., 2018; Cheng et al., 2019). The discrepancy may be attributed to the test methodology or the geographic variation of samples ( $\mathrm{Yu}$ et al., 2016). In addition, E. coli isolates have high resistance to first-generation cephalosporins (cefazolin, $32.60 \%$ ), but lower resistance to the second, third and fourth-generation cephalosporins (cefamandole, 4.42\%; ceftizoxime, $3.31 \%$; cefepime, $4.42 \%$ ). This suggests that first-generation cephalosporins might have been widely misused in the environment in past decades thus reducing susceptibility and efficiency in the treatment of bacterial infections (Sudha et al., 2014). However, the accumulation of other generations of cephalosporins resulting in increased drug-resistant bacteria in the environment might take a longer time (Yu et al., 2016). Furthermore, the third- and fourth-generation cephalosporins, meropenem and polymyxin B tested in our study are regarded as critically important antimicrobial agents in human medicine by the (World Health Organization, 2019). Furthermore, polymyxin B was originally found in the Gram-positive bacterium Paenibacillus polymyxa as the last line of defense against serious infections with Gram-negative pathogens (Sun et al., 2018a). Meropenem belongs to the carbapenem class of $\beta$-lactams and has a broad-spectrum antibacterial activity (Cheng et al., 2019). Unfortunately, E. coli isolates from all three aquatic products exhibited high rates of resistance to polymyxin B (overall 27.62\%) and Pacific mackerel samples exhibited a resistance rate of $11.67 \%$ to meropenem. In China, antibiotics including doxycycline, sulfadiazine, florfenicol and neomycin are permitted in the aquaculture industry (PRC, 2019). Except for neomycin (overall resistance 2.21\%), however, more than $20 \%$ of isolates showed resistance to these antibiotics, which may result in reducing the efficiency of such antibiotics. Furthermore, we observed some resistance to furazolidone (overall 29.83\%) and chloramphenicol (overall 17.68\%), which have already been banned in aquaculture in China since 2002 and lomefloxacin (overall 10.50\%), which has been banned in aquaculture in China since 2015 (PRC, 2019). Thus, although certain antibiotics have been banned, the residues of resistance in bacteria can last for a long time. Finally, E. coli isolates exhibited resistance to older antibiotics trimethoprim-sulfamethoxazole (overall $20.44 \%$ ) and spectinomycin (overall $4.97 \%$ ), that have been used commonly in animal husbandry in China for many years (Gong et al., 2013).

Among the 181 E. coli isolates, 65.19\% (118/181) exhibited MDR and the MDR rates of three species of aquatic samples were all higher than $50 \%$. This is higher than the findings in our previous report (Cheng et al., 2019). A national surveillance study showed high levels of MDR E. coli isolates in pigs $(90.00 \%, 6,806 / 7562)$ and in chickens $(89.20 \%, 6,751 / 7,568)$ in China from 2008-2015 (Zhang et al., 2017). Although E. coli isolates of aquatic products in the present study had a relatively lower level of MDR compared to the very high levels found in the pig and the chicken isolates in China mentioned above, there is growing evidence that the problem with MDR bacteria is becoming serious in China and guidelines and regulations are urgently needed to limit and rationalize antimicrobial use (Yassin et al., 2017). Furthermore, we determined MAR index values of more than 0.2 in $62.43 \%$ of the isolates, which were distributed diversely in the three aquatic products. An MAR index value higher than 0.2 indicates that the aquatic products originated from a source of high-risk antimicrobial contamination. The MAR index is used to evaluate the extent of environmental contamination by antimicrobials (Krumperman, 1983). Moreover, the MAR index value of two isolates sourced from Pacific mackerels was 0.68 , which exhibited resistance to 13 antibiotics. These all implied that most aquatic products were extensively exposed to antimicrobials.

According to past studies, integrons are as one of the MGEs that play a vital role in the development and dissemination of ARGs and MDR bacteria (Stalder et al., 2012). In our study, class 1 integrons were the most common type, followed by class 2 integrons and no class 3 integrons were detected, which was consistent with some other studies showing that the predominance of 
class 1 integrons was in animal-derived E. coli and human-associated Gram-negative isolates (Paraoan et al., 2017; Rehman et al., 2017). Meanwhile, all integronpositive strains are MDR in our study.

Of the 56 class 1 integron-positive isolates, 31 had GCs and nine different GC arrays were detected. The most prevalent genes detected in the VRs of integrons were those encoding adenylyl transferases (aadAl, $\operatorname{aad} A 2$, $a a d A 5$ and $a a d B)$ and dihydrofolate reductase (dfrA1, dfrA12 and $d f r A 17)$, which are responsible for streptomycin-spectinomycin and trimethoprim resistance, respectively (Rehman et al., 2017). The aadA and $d f r A$ genes occurred alone or in combination with other resistance genes in 33 integron-positive isolates in our study and are reported highly stable in integrons, even in the absence of selective pressures, because of the low fitness cost of their structures (Paraoan et al., 2017; Dib et al., 2018; Fang et al., 2019). Additionally, two isolates from Pacific whiteleg shrimp samples carried the GC arr-3-aac (6')-Ib, which has been reported as one of the most common GC arrays in China and the reason for this requires further study (Acosta-Pérez et al., 2015; Hu et al., 2016; Sun et al., 2018b). Moreover, the $c m l A$ gene cassette was found in two isolates from Pacific whiteleg shrimp samples. This cassette encodes a chloramphenicol efflux pump located in both the plasmids and chromosomes and may be responsible for acquired or intrinsic resistance to chloramphenicol (Acosta-Pérez et al., 2015). Meanwhile, $44.64 \%(25 / 56)$ of class 1 integronpositive isolates lacked GCs despite harboring an intII gene and exhibiting MDR. Some researchers believe that such bacteria have the potential to rapidly capture antibiotic resistance genes and acquire antibiotic resistance (Kotlarska et al., 2015; Park et al., 2018).

Of the five class 2 integron-positive isolates in our study, two different GC arrays were detected. The GCs dfrA1-sat2-aadAl were found most frequently associated with Class 2 integrons and the sat 2 gene cassette encodes streptomycin acetyltransferase, which results in streptomycin resistance (Xia et al., 2013; Mostafa et al., 2015; Paraoan et al., 2017). Additionally, one isolate was found to carry the GC array dfrA1-catB2-sat2-aadA1, which has been reported by a few studies, such as in Morganella morganii from clinical specimens, in Providencia spp., Proteus spp. and Proteus vulgaris from wastewater environments and in Proteus, Aeromonas, Staphylococcus, Citrobacter and Shewanella from eels and aquaculture ponds (Lin et al., 2016; Cao et al., 2017; Moreira et al., 2019). The intI2 gene contains an internal stop codon (TAA) at position 179 yielding and inactive 178-amino acid polypeptide, which might be the reason that occurrence of class 2 integrons is much lower than class 1 integrons (Hansson et al., 2002; Lin et al., 2016). In our study, all intI2-positive strains also carried intIl, which suggests that class 2 integrons can be complemented in trans by intIl (Hansson et al., 2002; Xia et al., 2013). In addition, we did not detect class 3 integrons. However, class 3 integrons were mostly detected in clinical and environmental samples such as in Enterobacter cloacae and Delftia spp. from hospital effluent and environmental sources, respectively (Xu et al., 2007; Barraud et al., 2013).

\section{Conclusion}

In conclusion, we analyzed the antimicrobial resistance profiles and integrons and their associated GCs of E. coli strains isolated from three species of aquatic products sold at different markets in Zhejiang Province, China. It showed that a total of 181 (40.22\%) E. coli isolates were obtained from the 150 Pacific whiteleg shrimps, 150 Pacific mackerels and 150 Pacific oysters samples. Overall, the highest resistance rate observed in the isolates was to enrofloxacin (59.12\%) and the resistance pattern in the isolates was highly variable and significant differences were observed between seven antibiotics $(p<0.05)$. Furthermore, $65.19 \%(118 / 181)$ of the isolates exhibited Multi-Drug Resistance (MDR) and the multiple resistance patterns were highly diverse with 77 different ones. Additionally, multiple-antibiotic resistance index values of more than 0.2 were determined in $62.43 \%$ of the isolates, which were diversely distributed in the three aquatic products. Of the $181 \mathrm{E}$. coli isolates obtained, 56 (30.94\%) were positive for class 1 integrons and five $(2.76 \%)$ were positive for class 2 integrons. Among these, $31 \mathrm{GCs}$ with nine different arrays were detected in class 1 integrons and five GCs with two different arrays were detected in class 2 integrons. This study suggests that aquatic products may act as a reservoir for MDR bacteria and facilitate the dissemination of ARGs. Continuous surveillance targeting AMR bacteria from aquatic products is necessary to ensure safe consumption. Furthermore, strict preventive measures should be taken to avoid the spread of ARGs and MDR bacteria in aquatic products in China, as well as worldwide.

\section{Acknowledgment}

This research was supported by the National Natural Science Foundation of China under Grant Nos. 31901792 and 31801655 and the Zhejiang Provincial Natural Science Foundation of China under Grant No. LQ18C200004 and 2019 University Students of Zhejiang Science and Technology Innovation Activity Fund (New Talent Program) No. 2019R409059.

\section{Author Contributions}

Ting Yu and Han Jiang: Completed the analysis of gene cassettes and all data analysis and prepared the manuscript. 
Hui Cheng and Yingwen Chen: Completed antibiotic resistance testing and integron class and gene cassette detection.

Yiru Xuan, Xiang Lv, Yihao Chen and Jingyi Gu: Completed sample collection and E. coli isolation and identification.

Jiehong Fang and Cheng Zhu: Designed the project, completed the data analysis and revised the manuscript.

\section{Ethics}

This article is original and contains unpublished material. The corresponding author confirms that all of the other authors have read and approved the manuscript and no ethical issues involved.

\section{Reference}

Acosta-Pérez, G., Ibáñez-Cervantes, G., Bello-López, J. M., Hernández, J. M., Hernández-Montañez, Z., Giono-Cerezo, S., ... \& León-Avila, G. (2015). Structural diversity of class 1 integrons in multiresistant strains of Escherichia coli isolated from patients in a hospital in Mexico City. Current microbiology, 71(4), 501-508.

Baharoglu, Z., Bikard, D., \& Mazel, D. (2010). Conjugative DNA transfer induces the bacterial SOS response and promotes antibiotic resistance development through integron activation. PLoS Genet, 6(10), e1001165.

Barraud, O., Casellas, M., Dagot, C., \& Ploy, M. C. (2013). An antibiotic-resistant class 3 integron in an Enterobacter cloacae isolate from hospital effluent. Clinical Microbiology and Infection, 19(7), E306-E308.

Barraud, O., \& Ploy, M. C. (2015). Diversity of class 1 integron gene cassette rearrangements selected under antibiotic pressure. Journal of bacteriology, 197(13), 2171-2178.

Beridze, M., Kal andia, A., Japaridze, I., Vanidze, M., Varshanidze, N., Turmanidze, N., ... \& Jakeli, E. (2020). Phytochemical Study of Endemic Species Helleborus Caucasicus and Helleborus Abchasicus. HighTech and Innovation Journal, 1(1), 28-32.

Cabello, F. C., Godfrey, H. P., Tomova, A., Ivanova, L., Dölz, H., Millanao, A., \& Buschmann, A. H. (2013). Antimicrobial use in aquaculture re-examined: its relevance to antimicrobial resistance and to animal and human health. Environmental microbiology, 15(7), 1917-1942.

Cao, J., Li, M., Xu, C., Zhou, T., Du, J., Sun, Y., ... \& $\mathrm{Xu}$, J. (2017). Characterization of Integrons and qnr Genes in Proteeae from a Teaching Hospital in China. Chemotherapy, 62(1), 12-18.
Cheng, H., Jiang, H., Fang, J., \& Zhu, C. (2019). Antibiotic Resistance and Characteristics of Integrons in Escherichia coli Isolated from Penaeus vannamei at a Freshwater Shrimp Farm in Zhejiang Province, China. Journal of food protection, 82(3), 470-478.

CLSI. (2019). Performance standards for antimicrobial susceptibility testing. 29th ed. CLSI supplement M100. Clinical and Laboratory Standards Institute, USA. https://clsi.org/media/2663/m100ed29_sample.pdf

Dib, A. L., Agabou, A., Chahed, A., Kurekci, C., Moreno, E., Espigares, M., \& Espigares, E. (2018). Isolation, molecular characterization and antimicrobial resistance of enterobacteriaceae isolated from fish and seafood. Food Control, 88, 54-60.

Dokić, D., Gavran, M., Gregić, M., \& Gantner, V. (2020). The Impact of Trade Balance of Agri-Food Products on the State's Ability to Withst and the Crisis. HighTech and Innovation Journal, 1(3), 107-111.

Ebrahimipour, G., Avini, M. Y., \& Ghorbanmovahhed, M. (2020). Isolation and Characterization of Glutaminasefree L-asparaginase Produced by Staphylococcus sp. MGM1. SciMedicine Journal, 2(2), 46-55.

Fang, J., Shen, Y., Qu, D., \& Han, J. (2019). Antimicrobial resistance profiles and characteristics of integrons in Escherichia coli strains isolated from a large-scale centralized swine slaughterhouse and its downstream markets in Zhejiang, China. Food control, 95, 215-222.

FAO. (2002). Fishery statistics capture production. FAO. http://www.fao.org/3/a-y5434t.pdf

Gong, J., Xu, M., Zhu, C., Miao, J., Liu, X., Xu, B., ... \& Jia, X. (2013). Antimicrobial resistance, presence of integrons and biofilm formation of Salmonella Pullorum isolates from eastern China (1962-2010). Avian Pathology, 42(3), 290-294.

Hansson, K., Sundström, L., Pelletier, A., \& Roy, P. H. (2002). IntI2 integron integrase in Tn7. Journal of bacteriology, 184(6), 1712-1721.

He, Y., Jin, L., Sun, F., Hu, Q., \& Chen, L. (2016). Antibiotic and heavy-metal resistance of Vibrio parahaemolyticus isolated from fresh shrimps in Shanghai fish markets, China. Environmental Science and Pollution Research, 23(15), 15033-15040.

Hochhut, B., Lotfi, Y., Mazel, D., Faruque, S. M., Woodgate, R., \& Waldor, M. K. (2001). Molecular analysis of antibiotic resistance gene clusters in Vibrio cholerae O139 and O1 SXT constins. Antimicrobial agents and chemotherapy, 45(11), 2991-3000.

Hu, L. F., Chen, G. S., Kong, Q. X., Gao, L. P., Chen, X., Ye, Y., \& Li, J. B. (2016). Increase in the prevalence of resistance determinants to trimethoprim/sulfamethoxazole in clinical Stenotrophomonas maltophilia isolates in China. PLoS One, 11(6), e0157693. 
Huddleston, J. R. (2014). Horizontal gene transfer in the human gastrointestinal tract: potential spread of antibiotic resistance genes. Infection and drug resistance, $7,167$.

Jiang, H., Cheng, H., Liang, Y., Yu, S., Yu, T., Fang, J., \& Zhu, C. (2019). Diverse mobile genetic elements and conjugal transferability of sulfonamide resistance genes (sul1, sul2 and sul3) in Escherichia coli isolates from Penaeus vannamei and pork from large markets in Zhejiang, China. Frontiers in microbiology, 10, 1787.

Kang, C. H., Shin, Y., Yu, H., Kim, S., \& So, J. S. (2018). Antibiotic and heavy-metal resistance of Vibrio parahaemolyticus isolated from oysters in Korea. Marine pollution bulletin, 135, 69-74.

Kotlarska, E., Łuczkiewicz, A., Pisowacka, M., \& Burzyński, A. (2015). Antibiotic resistance and prevalence of class 1 and 2 integrons in Escherichia coli isolated from two wastewater treatment plants and their receiving waters (Gulf of Gdansk, Baltic Sea, Pol and). Environmental Science and Pollution Research, 22(3), 2018-2030.

Krumperman, P. H. (1983). Multiple antibiotic resistance indexing of Escherichia coli to identify high-risk sources of fecal contamination of foods. Applied and Environmental Microbiology, 46(1), 165-170.

Lae, K. Z. W., Su, S. S., Win, N. N., Than, N. N., \& Ngwe, H. (2019). Isolation of Lasiodiplodin and Evaluation of some Biological Activities of the Stem Barks of Phyllanthus Albizzioides (Kurz) Hook. f. SciMedicine Journal, 1(4), 199-216.

Li, Q., Zhao, P., Li, L., Zhao, H., Shi, L., \& Tian, P. (2020). Engineering a CRISPR interference system to repress a class 1 integron in Escherichia coli. Antimicrobial agents and chemotherapy, 64(3).

Li, Y., Yang, L., Fu, J., Yan, M., Chen, D., \& Zhang, L. (2018). Genotyping and high flux sequencing of the bacterial pathogenic elements-integrons. Microbial pathogenesis, 116, 22-25.

Lin, M., Wu, X., Yan, Q., Ma, Y., Huang, L., Qin, Y., \& $\mathrm{Xu}, \mathrm{X}$. (2016). Incidence of antimicrobial-resistance genes and integrons in antibiotic-resistant bacteria isolated from eels and aquaculture ponds. Diseases of Aquatic Organisms, 120(2), 115-123.

Liu, X. J., Lyu, Y., Li, Y., Xue, F., \& Liu, J. (2017). Trends in antimicrobial resistance against enterobacteriaceae strains isolated from blood: A 10-year epidemiological study in mainl and China (2004-2014). Chinese Medical Journal, 130(17), 2050.

Luo, Y., Mao, D., Rysz, M., Zhou, Q., Zhang, H., Xu, L., \& JJ Alvarez, P. (2010). Trends in antibiotic resistance genes occurrence in the Haihe River, China. Environmental science \& technology, 44(19), 7220-7225.
Manikandan, G., Yuvashree, M., Sangeetha, A., Bhuvana, K. P., \& Nayak, S. K. (2020). Liver Tissue Regeneration using Nano Silver impregnated Sodium Alginate/PVA Composite Nanofibres. SciMedicine Journal, 2(1), 16-21.

Martínez, J. L. (2008). Antibiotics and antibiotic resistance genes in natural environments. Science, 321(5887), 365-367.

Moreira, A., Couvé-Deacon, E., Bousquet, P., Chainier, D., Jové, T., Ploy, M. C., \& Barraud, O. (2019). Proteae: a reservoir of class 2 integrons? Journal of Antimicrobial Chemotherapy, 74(6), 1560-1562.

Mostafa, M., Siadat, S. D., Shahcheraghi, F., Vaziri, F., Japoni-Nejad, A., Yousefi, J. V., ... \& Rahbar, M. (2015). Variability in gene cassette patterns of class 1 and 2 integrons associated with multi drug resistance patterns in Staphylococcus aureus clinical isolates in Tehran-Iran. BMC microbiology, 15(1), 152.

Odumosu, B. T., Adeniyi, B. A., \& Ch andra, R. (2013). Analysis of integrons and associated gene cassettes in clinical isolates of multidrug resistant Pseudomonas aeruginosafrom Southwest Nigeria. Annals of clinical microbiology and antimicrobials, 12(1), 29.

Paraoan, C. E. M., Rivera, W. L., \& Vital, P. G. (2017). Detection of Class I and II integrons for the assessment of antibiotic and multidrug resistance among Escherichia coli isolates from agricultural irrigation waters in Bulacan, Philippines. Journal of Environmental Science and Health, Part B, 52(5), 306-313.

Park, J. H., Kim, Y. J., \& Seo, K. H. (2018). Spread of multidrug-resistant Escherichia coli harboring integron via swine farm waste water treatment plant. Ecotoxicology and environmental safety, 149, 36-42.

PRC. (2019). Fisheries and Fisheries Administration of the Ministry of Agriculture and Rural Affairs. Aquaculture Medication Paper No. 1 and 2. http://www.yyj.moa.gov.cn/gzdt/201909/t20190923 6328674.htm

Rehman, M. U., Zhang, H., Huang, S., Iqbal, M. K., Mehmood, K., Luo, H., \& Li, J. (2017). Characteristics of Integrons and Associated Gene Cassettes in Antibiotic-Resistant Escherichia coli Isolated from Free-Ranging Food Animals in China. Journal of food science, 82(8), 1902-1907.

Shaikh, S., Fatima, J., Shakil, S., Rizvi, S. M. D., \& Kamal, M. A. (2015). Antibiotic resistance and extended spectrum beta-lactamases: Types, epidemiology and treatment. Saudi journal of biological sciences, 22(1), 90-101.

Shao, S., Hu, Y., Cheng, J., \& Chen, Y. (2018). Research progress on distribution, migration, transformation of antibiotics and antibiotic resistance genes (ARGs) in aquatic environment. Critical Reviews in Biotechnology, 38(8), 1195-1208. 
Shimizu, A., Takada, H., Koike, T., Takeshita, A., Saha, M., Nakada, N., ... \& Tuyen, B. C. (2013). Ubiquitous occurrence of sulfonamides in tropical Asian waters. Science of the total environment, 452, 108-115.

Stalder, T., Barraud, O., Casellas, M., Dagot, C., \& Ploy, M. C. (2012). Integron involvement in environmental spread of antibiotic resistance. Frontiers in microbiology, 3, 119.

Schwarz, S., Silley, P., Simjee, S., Woodford, N., van Duijkeren, E., Johnson, A. P., \& Gaastra, W. (2010). Assessing the antimicrobial susceptibility of bacteria obtained from animals. Journal of antimicrobial chemotherapy, 65(4), 601-604.

Sudha, S., Mridula, C., Silvester, R., \& Hatha, A. A. M. (2014). Prevalence and antibiotic resistance of pathogenic Vibrios in shellfishes from Cochin market.

Sun, J., Zhang, H., Liu, Y. H., \& Feng, Y. (2018a). Towards understanding MCR-like colistin resistance. Trends in microbiology, 26(9), 794-808.

Sun, W., Gu, J., Wang, X., Qian, X., \& Tuo, X. (2018b). Impacts of biochar on the environmental risk of antibiotic resistance genes and mobile genetic elements during anaerobic digestion of cattle farm wastewater. Bioresource technology, 256, 342-349.

Tan, C. W., Malcolm, T. T., Kuan, C. H., Thung, T. Y., Chang, W. S., Loo, Y. Y., ... \& Rukayadi, Y. (2017). Prevalence and antimicrobial susceptibility of Vibrio parahaemolyticus isolated from short mackerels (Rastrelliger brachysoma) in Malaysia. Frontiers in microbiology, 8, 1087.

Theingi, M., Tun, K. T., \& Aung, N. N. (2019). Preparation, Characterization and Optical Property of LaFeO3 Nanoparticles via Sol-Gel Combustion Method. SciMedicine Journal, 1(3), 151-157.

Top, E. M., \& Springael, D. (2003). The role of mobile genetic elements in bacterial adaptation to xenobiotic organic compounds. Current Opinion in Biotechnology, 14(3), 262-269.
Trang, G. T. T., Linh, N. H., Linh, N. T. T., \& Kien, P. H. (2020). The Study of Dynamics Heterogeneity in $\mathrm{SiO} 2$ Liquid. HighTech and Innovation Journal, 1(1), 1-7.

White, P. A., McIver, C. J., \& Rawlinson, W. D. (2001). Integrons and gene cassettes in the enterobacteriaceae. Antimicrobial agents and chemotherapy, 45(9), 2658-2661.

World Health Organization. (2019). Critically important antimicrobials for human medicine.

Xia, R., Ren, Y., Guo, X., \& Xu, H. (2013). Molecular diversity of class 2 integrons in antibiotic-resistant gram-negative bacteria found in wastewater environments in China. Ecotoxicology, 22(2), 402-414.

$\mathrm{Xu}$, H., Davies, J., \& Miao, V. (2007). Molecular characterization of class 3 integrons from Delftia spp. Journal of Bacteriology, 189(17), 6276-6283.

Yassin, A. K., Gong, J., Kelly, P., Lu, G., Guardabassi, L., Wei, L., ... \& Wang, C. (2017). Antimicrobial resistance in clinical Escherichia coli isolates from poultry and livestock, China. PloS one, 12(9), e0185326.

Yu, Q., Niu, M., Yu, M., Liu, Y., Wang, D., \& Shi, X. (2016). Prevalence and antimicrobial susceptibility of Vibrio parahaemolyticus isolated from retail shellfish in Shanghai. Food control, 60, 263-268.

Zhang, P., Shen, Z., Zhang, C., Song, L., Wang, B. Shang, J., ... \& Zheng, Y. (2017). Surveillance of antimicrobial resistance among Escherichia coli from chicken and swine, China, 2008-2015. Veterinary microbiology, 203, 49-55.

Zhang, Q. Q., Ying, G. G., Pan, C. G., Liu, Y. S., \& Zhao, J. L. (2015). Comprehensive evaluation of antibiotics emission and fate in the river basins of China: source analysis, multimedia modeling and linkage to bacterial resistance. Environmental science \& technology, 49(11), 6772-6782.

Zhu, Y. G., Gillings, M., Simonet, P., Stekel, D., Banwart, S., \& Penuelas, J. (2017). Microbial mass movements. Science, 357(6356), 1099-1100. 